\title{
Um retrato dos filhos de criação na imprensa brasileira ${ }^{1}$
}

\author{
Adriana Pellanda Gagno \\ Lidia Natalia Dobrianskyj Weber \\ Universidade Federal do Paraná
}

\begin{abstract}
Resumo
A prática conhecida como filho de criação ou circulação de crianças é encontrada em vários lugares do mundo, inclusive no Brasil. Diferente do filho adotivo, cuja relação de filiação é substitutiva à relação dada biologicamente, o filho de criação possui uma relação de filiação aditiva. Considerando a centralidade dos meios de comunicação de massa na cultura contemporânea, objetivou-se com esta pesquisa descrever e analisar as representações relativas aos filhos de criação veiculadas por duas revistas brasileiras de circulação nacional, em reportagens e cartas de leitores, nos períodos de 1975 a 1979 e de 1996 a 2000. O método utilizado foi a análise de conteúdo. Os resultados apontaram para a quase inexistência de menções a tal prática no Brasil. Acredita-se que o fato desta forma de organização de parentesco ser mais comum entre os pobres urbanos, aliado à falta de estudos sistemáticos, fez com que o assunto não fosse considerado relevante ou fosse mesmo desconhecido dos agentes dos media. Salienta-se, por isso, a necessidade de mais pesquisas sobre esta forma tradicional de filiação e, em particular, sugere-se a realização de pesquisas transdisciplinares sobre a saúde mental dos brasileiros que "circularam" por diferentes famílias durante a infância e a adolescência e seus sentimentos e representações em relação a esta prática.

Palavras-chave: filhos de criação; circulação de crianças; imprensa brasileira.
\end{abstract}

\begin{abstract}
The portrayal of foster children by the Brazilian press

The practice of "child-fostering", or the placement of children with a succession of different families, can be found in various parts of the world, including Brazil. In contrast to adoption, where the relationship with the adoptive parents replaces that of the biological parents, the relationship with a foster child is simply that of supporting an additional child. Taking into consideration that the mass media has a centralizing role in contemporary culture, the purpose of this research is to describe and analyse the portrayal of foster children by two Brazilian nationwide magazines. To this end, the method known as "contents analysis" was used; based on articles and readers' letters between 1975 and 1979 and again for those published between 1996 and 2000. The results indicate a virtual nonexistence of references to the practice of child-fostering in Brazil. Although this form of family relationship is most common among the urban underprivileged population, the issue has been considered irrelevant, if not unknown to the media, due to the lack of systematic study. For this reason, research into this form of parenthood is needed. In particular, trans-disciplinary research should be done in regard to the mental health of Brazilians who have been placed with a "succession" of different families during their childhood and teenage years.

Keywords: foster children; child placement with a succession of families; Brazilian press.
\end{abstract}

"Não há uma família. A antropologia mostra, através de seus estudos, a existência de vários tipos de família e de diversos sistemas de parentesco".

Velho (1987, p. 80) 
Inicialmente, julga-se necessário esclarecer que filho de criação não é, aqui, sinônimo de filho adotivo. Apesar de estas expressões serem usadas no senso comum indistintamente, a literatura (Costa, 1988; Fonseca, 1995, 1999, 2000; Abreu, 1998; Weber, 2001) aponta para diferenças importantes entre estas duas formas de constituição familiar.

Enquanto na adoção - tanto legal (realizada através do Juizado da Infância e da Juventude) quanto informal (quando a criança é registrada como se fosse filho legítimo) - a relação de filiação estabelecida é substitutiva à relação dada biologicamente, nas famílias de criação a relação de filiação é geralmente aditiva. Assim, o filho de criação dispensa a preocupação com a evitação de relações com a família de origem, em contraste com a experiência de adoção, na qual, via de regra, a família adotiva e a família biológica não se conhecem.

Os filhos de criação, ao terem uma relação de filiação aditiva, "somam mães" - nas palavras de Fonseca (1995) - ao invés de substituir a mãe biológica pela adotiva, como acontece com os filhos adotivos. Os etnólogos, ainda segundo Fonseca (1995), chamam esta prática de "circulação de crianças", por causa do vai-e-vem de crianças entre as casas de diversas "mães" (genetriz, madrinha, vizinha, avó ou mãe de criação).

\section{A circulação de crianças no Brasil}

Fonseca (1995) considera a "circulação de crianças" tão comum que "não deveria ser ignorada nas análises de organização de família de baixa renda no Brasil" (p. 42). De fato, a literatura sobre este tema é bastante restrita. Praticamente apenas Fonseca realizou estudos sistemáticos a este respeito no país. Como ela mesma relata:

Perplexa, de início, pela falta de qualquer menção desta prática na literatura das Ciências Sociais, inclinei-me a pensar que tal fenômeno estava limitado às condições históricas do Sul do Brasil. Entretanto, pouco a pouco, de Recife a Belém, de Salvador a Porto Alegre, surgem dados mostrando que um número surpreendente de famílias urbanas de baixa renda abriga algum tipo de filho de criação (Fonseca, 1995, p. 14).

Conforme Fonseca $(1995$; 1999), a circulação de crianças é uma forma alternativa de organização de parentesco que não é vista pelos pais biológicos como abandono nem vivida como tal pelas próprias crianças. "De forma mais significativa, mesmo quando passa boa parte de sua infância numa família substi- tuta, o jovem não perde os vínculos com a família de origem e, freqüentemente, depois de crescer, volta a integrar sua rede consangüínea" (1999, p. 269). Os pais biológicos parecem ter o papel de fornecer à criança uma identidade por filiação biológica. Observa-se, portanto, grande diferença em relação à adoção legal ou mesmo à adoção informal (também conhecida como adoção à brasileira), nas quais a transferência de uma família para outra é completa.

A autora observa que não se deve atribuir a um determinismo econômico a prática da circulação de crianças no Brasil. A privação econômica seria um fator-chave para o entendimento deste fenômeno, mas não o único. Até porque, como indica Fonseca (1995), a circulação de crianças no Brasil tem sido comum entre os pobres urbanos do Brasil há pelo menos dois séculos: "Mesmo se certas práticas se iniciaram como estratégias de sobrevivência ad hoc, é inconcebível que, depois de dez gerações, não tenham adquirido um significado específico integrado a um modelo cultural" (p. 17).

Fonseca (1995) assinala que mesmo nas classes médias brasileiras a circulação de crianças teve seu lugar, pelo menos no sul do país:

As mulheres, mesmo depois de casadas, continuam a passar uma boa parte de seu tempo na casa dos pais, e estes, com frequiência, acabam ocupando-se dos netos quase em regime de tempo integral. Até mais ou menos vinte anos atrás, essa fluidez dos limites da família foi responsável por um número impressionante de adoções informais, onde uma mulher de classe média colocava um de seus filhos na casa de uma irmã solteira ou estéril. (Apenas no meu departamento na universidade, tenho três colegas que foram criadas em tais condições.) A frequiência desta prática indica não somente a importância da família extensa no sistema de parentesco brasileiro, mas, também, a influência particular da ideologia materna: evidentemente, essas mulheres, ao mesmo tempo que eram instruídas e relativamente abastadas, não temiam os danos psicológicos que podiam resultar do afastamento de uma criança de sua mãe biológica. Apesar da falta de pesquisas sistemáticas sobre este campo, arrisco a hipótese de que, durante a última geração, as crianças de classe média pararam de circular. Suas mães aprenderam a se angustiar conforme os ditames de Freud e do Dr. Spock. Com sua memória convenientemente curta, este grupo passou a condenar a circulação de crianças como uma prática de pais "desnaturados", usando-a para mar- 
car a distinção entre as famílias respeitáveis e as moralmente repreensíveis (p. 39-40).

Esta questão dos efeitos psicológicos da prática de circulação de crianças é bastante complexa. Os relatos de Fonseca $(1995 ; 1999)$ apontam para o fato de que tal experiência não traria necessariamente problemas para a criança. Muitos adultos que colocam crianças em circulação não as consideram seres particularmente frágeis e, por isso, não as consideram motivos de grandes preocupações. E as crianças que "circulam", mesmo sendo tratadas em desigualdade de condições em comparação com os filhos biológicos da família, "não demonstravam grandes ressentimentos e deixavam claro que estavam naquelas residências voluntariamente" - conforme estudo de Fonseca (1995, p. 34). Já a Psicologia acredita na importância de figuras estáveis de apego para que a criança possa se desenvolver satisfatoriamente. Como afirma Fonseca, não existem pesquisas brasileiras a respeito, especificamente, da saúde psicológica das pessoas que vivenciaram tal prática, sendo este um campo bastante importante para estudos transdisciplinares.

Foi encontrado o relato de um único estudo sobre a questão dos aspectos psicológicos envolvidos na prática da circulação de crianças. Goody (1982) relata que uma antropóloga, intrigada com o alto índice de circulação entre os Gonjas da África Ocidental, aplicou testes psicológicos para comparar tais crianças com as que estavam sendo criadas pelos seus próprios genitores e constatou que não houve diferença significativa entre os grupos, quanto ao equilíbrio emocional e ao sucesso social.

Alguns autores, tais como Weber (2001), também utilizam o termo "filho de criação" para referir-se aos casos de adoção informal na qual a certidão de nascimento da criança não é alterada, mantendo-se, portanto, no registro os nomes dos seus pais biológicos.

\section{A circulação de crianças no mundo}

O fenômeno da circulação de crianças é encontrado em vários lugares do mundo.

A prática de circulação de crianças (confiar a educação de crianças a terceiros) é tão arraigada na África que, em uma determinada comunidade, uma mulher não é a única que "espera" um bebê, mas também toda a comunidade "espera" por ele. Na África nãomuçulmana entende-se que as crianças vêm do mundo dos ancestrais, permanecem um tempo entre os vivos e, após a morte, retornam aos seus ancestrais. Desta forma, a criança pertence à sua linhagem, não à sua família (Ezembé, 1997).

Segundo Weber (2001), o conceito de circulação de crianças na África inclui a adoção e a doação.
Quem doa uma criança não têm vergonha de fazê-lo, e quem a recebe mostra gratidão, pois a criança é considerada uma riqueza. $\mathrm{O}$ objetivo desta prática é tornar a criança autônoma, proporcionando-lhe conhecimento sobre a vida do clã e fazendo-a compreender que o grupo familiar não se resume nos pais, mas estende-se a outras pessoas.

Goody (1982) revela que entre os Gonjas da África Ocidental a colocação de bebês em circulação se dá tanto por razões de divórcio quanto para estreitar laços de solidariedade interna das linhagens ou para receber formação profissional.

De acordo com Charles (1997), na Polinésia Francesa (Oceania) a parentalidade adotiva não exclui a biológica, e as crianças dividem seu tempo entre a sua família de sangue e a sua família adotiva. Nesta sociedade, a adoção é uma regra, sendo que a sua ausência é que requer uma explicação. As crianças circulam entre parentes e amigos, sendo esta prática considerada um gesto de amizade que não possui significado de abandono ou rejeição.

Na cultura esquimó um tipo de "adoção aberta", na qual família biológica e adotiva se encontram, também é praticado. Entre eles, a origem da criança nunca é ocultada e em muitos casos ela é considerada como pertencente a ambas as famílias. A criança pode chamar a ambos os casais de pais pelos mesmos nomes, e mantém fortes vínculos com ambos. Em estudos genealógicos empreendidos, antropólogos freqüentemente ficam confusos sobre quem são os pais biológicos de uma criança adotiva uma vez que ambos os casais a reivindicam. "É evidente que, quaisquer que sejam as razões para a adoção, os pais normalmente tratam a criança adotiva com tanto calor e afeição quanto o fazem com a sua própria"2 (Chance, 1966, citado por Sorosky; Baran \& Pannor, 1989, p. 209).

Salienta-se a importância de se estudar a circulação de crianças, a adoção e a filiação tendo em vista suas diferentes representações e práticas em diferentes culturas a fim de melhor compreender as nossas representações e práticas sobre o tema, e facilitar a desconstrução de vários preconceitos:

O trabalho da etnografia, ou pelo menos um deles, é realmente proporcionar, como a arte e a história, narrativas e enredos para redirecionar nossa atenção, mas não do tipo que nos torne aceitáveis a nós mesmos, representando os outros como reunidos em mundos a que não queremos nem podemos chegar, mas narrativas e enredos que nos tornem visíveis para nós mesmos, representando-nos e a todos os outros como jogados no meio de um mundo repleto de estranhezas irremovíveis, que não temos como evitar (Geertz, 2001, p. 82). 


\section{Como os filhos de criação são apresentados pela imprensa brasileira?}

Revendo a literatura, verificou-se a inexistência de estudos sobre as representações dos filhos de criação nos meios de comunicação de massa.

Considerando-se a necessidade de ampliar o conhecimento sobre este tipo de relação de filiação e visando preencher uma lacuna existente na literatura da área, resolveu-se realizar a presente pesquisa.

Salienta-se a importância de se conhecer o discurso da imprensa a respeito dos filhos de criação na medida em que os meios de comunicação de massa têm ocupado um lugar central na cultura contemporânea. Como afirma Luhmann, "o que nós sabemos sobre a nossa sociedade, sobre o mundo no qual vivemos, sabemos através dos meios de comunicação" (1995, citado por Sampaio, 2000). Neste sentido, acredita-se que a forma como os filhos de criação são apresentados pelos media acaba por impor-se como referência coletiva, a partir da qual os sujeitos elaboram sua própria compreensão da realidade.

\section{OBJETIVOS DA PESQUISA}

\section{Objetivo geral}

Descrever e analisar as representações relativas aos filhos de criação em textos veiculados por duas revistas brasileiras de circulação nacional, sendo uma de caráter informativo geral e outra especializada na área de família, nos períodos de 1975 a 1979 e de 1996 a 2000, é o objetivo da presente pesquisa.

\section{Objetivos específicos}

1. Verificar o número total de reportagens que tiveram por tema os filhos de criação;

2. Relacionar os aspectos mais freqüentemente abordados sobre filhos de criação;

3. Descrever e analisar o conteúdo das cartas (de leitores) publicadas na revista Pais \& Filhos sobre filhos de criação e as respectivas respostas dadas;

4. Caracterizar o discurso das revistas quanto ao tema, do ponto de vista dos significados atribuídos a tal prática;

5. Verificar se as representações dos filhos de criação, veiculadas pelas duas revistas, sofreram modificações no decorrer do tempo.

\section{MÉTODO}

A presente pesquisa é de tipo documental.
Artigos e cartas de leitores sobre filhos de criação veiculados pelas revistas Veja $^{3}$ e Pais \& Filhos ${ }^{4}$, nos períodos de 1975 a 1979 e de 1996 a 2000.

Delimitou-se como períodos para estudo: de 1975 a 1979, por serem anteriores aos anos 80, e de 1996 a 2000, por representarem a realidade contemporânea de modo a permitir acompanhar o percurso do tema adoção nos media através do tempo. O critério de recortar períodos de tempo anteriores e posteriores à década de 80 foi estabelecido em função de esta década ter sido apontada por Rizzini (1995) como sendo marco de uma mutação social, de um "amplo processo de mobilização social, sem paralelos na história da assistência à infância no Brasil" (p. 166), que constituiu terreno necessário até para a reformulação da legislação, vindo a desembocar no Estatuto da Criança e do Adolescente.

Sendo a periodicidade da revista Veja semanal e a da revista Pais \& Filhos mensal, foram analisadas, nestes dez anos de revisão de literatura, 518 revistas Veja e 113 revistas Pais \& Filhos, totalizando 631 revistas. É importante citar que a Editora Bloch faliu no ano de 2000, deixando de publicar as edições de agosto a dezembro da revista Pais \& Filhos deste ano ${ }^{5}$. As edições de março e abril de 1999 não puderam ser incluídas neste estudo devido a estarem em falta em todas as bibliotecas a que se teve acesso em Curitiba. Tentou-se localizá-las também em sebos, na editora atualmente responsável pela revista Nova Pais \& Filhos e a partir dos contatos pessoais da pesquisadora mas não se obteve sucesso.

\section{Procedimentos}

Selecionou-se para análise todos os artigos e notas que trataram especificamente sobre filhos de criação, independentemente da seção em que foram encontrados e também os artigos e notas que trataram dos filhos de criação como subtema. Estes foram obtidos pela leitura das publicações que trataram de temas relacionados, tais como família, esterilidade, genética, reprodução assistida, abandono de crianças, institucionalização, crianças em situação de risco, direitos da criança e do adolescente, violência contra crianças, maternidade, paternidade.

Os textos selecionados foram xerocados para posterior análise. Foi registrado se estes foram matérias de capa das revistas ou não.

\section{Análise de dados}

A codificação e a análise de dados foram feitas através do método da análise de conteúdo.

Cada reportagem foi classificada dentro de uma única categoria, que melhor a representasse. Além da construção e análise de categorias, foi também reali-

\section{Material}


zado um detalhamento dos conteúdos presentes em cada publicação, a fim de aprofundar a caracterização do discurso das revistas quanto ao tema.

\section{RESULTADOS E DISCUSSÃO}

Os dados obtidos serão apresentados em dois grupos: um referente às publicações das revistas Veja e Pais \& Filhos sobre filhos de criação, e outro sobre as cartas enviadas pelos leitores da revista Pais \& Filhos.

\section{Publicações sobre filhos de criação: panorama geral}

A Tabela 1 apresenta o número de publicações das revistas Pais \& Filhos e Veja que tiveram os filhos de criação como tema ou subtema, nos períodos de 1975 a 1979 e 1996 a 2000.

Tabela 1 - Número (freqüência) de notas e reportagens das revistas Pais \& Filhos e Veja que tiveram os filhos de criação como tema ou subtema, nos períodos de 1975 a 1979 e 1996 a 2000.

\begin{tabular}{lcccccccc}
\hline Períodos & \multicolumn{4}{c}{$1975-1979$} & \multicolumn{2}{c}{$1996-2000$} \\
\hline Revistas & \multicolumn{1}{c}{ Pais \& Filhos } & \multicolumn{3}{c}{ Veja } & \multicolumn{2}{c}{ Pais \& Filhos } & \multicolumn{2}{c}{ Veja } \\
\hline Categorias & notas & report. & notas & report. & notas & report. & notas & report. \\
Tema & 0 & 1 & 0 & 0 & 0 & 0 & 0 & 0 \\
Subtema & 0 & 0 & 0 & 2 & 0 & 1 & 0 & 1 \\
\hline TOTAL & 0 & 1 & 0 & 2 & 0 & 1 & 0 & 1 \\
\hline
\end{tabular}

Verifica-se, pela Tabela 1, a freqüência bastante baixa de reportagens e a ausência de notas publicadas nas referidas revistas sobre os filhos de criação, em ambos os períodos pesquisados. Em 631 revistas (resultado da soma de 518 revistas Veja com 113 revistas Pais \& Filhos), apenas uma vez esta forma de filiação foi tema de uma reportagem, ainda assim, sem que se utilizasse esta terminologia para se referir ao fenômeno. Acredita-se que o fato de esta forma de organização de parentesco ser mais comum entre os pobres urbanos fez com que o assunto não fosse considerado relevante para ser mencionado nas revistas, escritas para pessoas de outras classes sociais. A quase inexistência de estudos sobre os filhos de criação também pode ter colaborado para que estes não se tornassem visíveis nos meios de comunicação social.

\section{Detalhando os conteúdos das revistas Pais \& Filhos e Veja - 1975 a 1979}

Os dados coletados nas revistas Pais \& Filhos revelaram que, no período de 1975 a 1979, apenas um (1) artigo abordou diretamente os filhos de criação ou, mais especificamente, as mães de criação, não utilizando, contudo, esta terminologia para se referir ao fenômeno (Pais \& Filhos, mar/1976, p. 38-40). O artigo tratou sobre as "titias", irmãs de mães que por motivos de falecimento, doença ou imaturidade emocional não puderam criar seus filhos. Diz o artigo que tais mulheres "cuidam", "criam" ou "adotam afetivamente, sem transações legais de papéis" seus sobrinhos, "sendo a prova viva de um dos instintos inatos e mais poderosos da mulher: a maternidade" (Pais \& Filhos, mar/1976, p. 39). Os papéis de maternidade e paternidade, entretanto, são construídos socialmente, e não são simples manifestações do instinto. Especificamente sobre o "amor materno", Badinter (1980) esclarece,

ainda que esta conclusão pareça cruel, de que o amor maternal não passa de um sentimento, sendo, como tal, essencialmente contingente. Esse sentimento pode existir ou não existir; ser e desaparecer. Revelar-se forte ou frágil. Privilegiar um dos filhos ou dar-se a todos por igual. Tudo depende da mãe, da sua história e da História. Não, não há lei universal nesta matéria, que escapa ao determinismo natural. $\mathrm{O}$ amor maternal não é dado por si próprio. Existe "a mais", amor suplementar (p. 363).

Este artigo, de acordo com os sinais que podem ser observados no texto - tais como: não mencionar em nenhum momento a pobreza como um dos fatores que poderiam levar uma mãe a não poder criar seu filho; citar como exemplos dois casos nos quais os personagens que não podiam criar seus filhos eram um homem de negócios muito atarefado cuja esposa faleceu e uma atriz que precisava estar sempre viajando revelou a existência da circulação de crianças mesmo entre a classe média. Como explica Fonseca (1995), apenas "durante a última geração, as crianças de classe média pararam de circular" (p. 40).

Indiretamente, isto é, como subtema, os filhos de criação não foram citados nas revistas Pais \& Filhos deste período (1975 a 1979). 
Na revista Veja, neste mesmo período, nenhuma reportagem teve como tema a circulação de crianças. Mas duas (2) reportagens trouxeram a questão dos filhos de criação como subtema:

1. numa tratou-se sobre a chegada ao Brasil de refugiados portugueses de Angola e Moçambique, e foi citado um caso no qual uma das refugiadas, "Violeta Bundo (sobrenome de sua origem tribal), uma das raras refugiadas negras, [...] sem recursos financeiros e com cinco filhos menores", relatou: "Estou gostando muito daqui, pois chegamos no domingo e, já hoje, duas famílias bondosas levaram duas de minhas filhas para criar" (15.10.1975, p. 30);

2. noutra, expôs-se o caso de uma menina de dez anos de idade que foi seqüestrada e morta, e citou-se que o responsável pelo crime foi denunciado "por seu próprio irmão de criação". Neste caso, portanto, nem se tratou da questão das famílias de criação, apenas foi citado o termo "de criação", como qualificativo da relação de parentesco existente (11.10.1978, p. 36).

É interessante notar, em relação à primeira destas reportagens, que a refugiada não se queixou de não ter recebido ajuda suficiente para ficar com suas filhas, mas antes agradeceu a generosidade de outros cuidarem delas em seu lugar. Ela interpretou esse ato como sendo de solidariedade, retratando o caráter habitualmente atribuído na África à prática da circulação de crianças, aspecto abordado anteriormente neste artigo.

\section{Detalhando os conteúdos das revistas Pais \& Filhos e Veja - 1996 a 2000}

Entre 1996 e 2000 nenhuma reportagem teve os filhos de criação por tema. Talvez haja relação entre este fato e a hipótese de Fonseca (1995) de que as crianças de classe média tenham parado de circular nesta última geração. Como explica a autora, na classe média o modelo dominante de família é, cada vez mais, centrado na família conjugal, e os parentes consangüíneos ocupam um lugar secundário. Nas famílias das camadas médias, as crianças são o foco da unidade conjugal, nas quais se "investe" para a construção de um projeto familiar de longo prazo.

Já a prática de circulação de crianças faz parte de um outro tipo de família, no qual os laços de sangue, a solidariedade entre os membros da rede consangüínea, são mais fortes e importantes do que o vínculo do casal. As crianças "são consideradas não como indivíduos singulares, mas sim como partes integrantes do grupo" (Fonseca, 1995, p. 39).

Neste período, na revista Pais \& Filhos, apenas uma vez os filhos de criação foram subtema de reportagem. Foi em maio de 2000 (p. 35), na coluna Vida
\& Bem-Estar, assinada por Rosinha Matheus, na época Primeira Dama do Estado do Rio de Janeiro e Secretária Estadual de Ação Social. Trata-se de um artigo sobre o Dia das Mães, no qual ela afirma que não existem "tipos" de mãe:

Ser mãe. Muitos já tentaram definir o que vem a ser isso. Mãe é quem põe no mundo ou quem cuida? Mãe biológica, mãe adotiva e mãe de criação são termos que muitos empregam, como se existissem categorias, tipos de mãe. Não há. Falo por experiência própria, como mulher que, além de dar à luz quatro filhos, tomou como seus outros cinco, gerados por outras (maio/2000, p. 35).

A literatura parece contradizê-la, pois mostra que nem sempre os filhos de criação são tratados de forma igual aos filhos "de sangue"... mas, ainda assim, são filhos, considerando-se que não existe uma única maneira, dada pela natureza, de se exercer a paternidade e a maternidade. Como ensina a Antropologia, devese buscar compreender "outras" lógicas e saber situar a "nossa" lógica como uma entre outras (Fonseca, 1999, p. 270), apesar de isto nem sempre ser fácil.

A idéia da diferença cria, compreensivelmente, problemas - mais ainda quando é ligada, como na sociedade de classes, à desigualdade e injustiça. Seria muito conveniente poder dizer que, no fundo, não há nenhuma diferença no sentimento de pais para com seus filhos onde quer que estejamos. Não teríamos que considerar a possibilidade de valores diferentes dos nossos. Poderíamos nos tranqüilizar com a validade universal de nosso próprio mundo simbólico. Entretanto, a antropologia dos últimos anos tem martelado no fato de que um valor deve ser visto como produto de seu contexto. $\mathrm{O}$ teor preciso das sensibilidades familiares ou da noção de infância é produzido por circunstâncias históricas específicas. É bem possível que o sitiante paulistano pensa seus filhos de uma maneira, o sapateiro gaúcho de outra, e o professor universitário carioca de outra maneira ainda. Da parte do pesquisador, esse reconhecimento da diferença não implica - como querem certos críticos do relativismo - uma omissão moral. Procurar compreender a lógica subjacente a determinada prática social não equivale aprovar nem advogar a manutenção desta prática. É aceitar o princípio básico do diálogo - a dúvida de que seus interlocutores tenham algo a dizer que vale a pena escutar (Fonseca, 1999, p. 269279). 
Na revista Veja, em reportagem sobre crianças infratoras institucionalizadas, há uma menção à "avó de criação" de um dos meninos internos na Febem (15.10.1997, p. 98-103). Diz a reportagem que "Jonas (furto), de 12 anos, não se cabe de felicidade porque a avó que o criou, Teresa Menezes dos Santos, não se esqueceu da visita. Ela o abraça e beija e se enche de esperança. 'Acho que agora ele toma juízo', diz" (15.10.1997, p. 101).

Salienta-se que os filhos de criação nunca foram tema de entrevista nas páginas amarelas da Veja. Também não foram matéria de capa da revista Pais \& Filhos ou da Veja.

Essa escassez de reportagens mostra a dificuldade da sociedade e dos media de levar em consideração que "numa mesma sociedade complexa, podem coexistir diversas configurações familiares" (Fonseca, 1999, p. 261).

\section{Cartas sobre filhos de criação - Pais \& Filhos: 1975 a 1979 e 1996 a 2000}

No período de 1975 a 1979, havia duas seções que respondiam a cartas de leitores. Uma era a coluna do Dr. Haroldo Lins e Silva, intitulada "Você frente a frente com o advogado de família", e outra era a seção de cartas sobre os demais assuntos ligados à família, intitulada "Cartas" e, posteriormente, "Pais \& Filhos Escrevem". As cartas enviadas para esta última seção, até o mês de julho de 1975, eram respondidas sob a coordenação do pediatra Thales Pontes Luz. A partir de agosto de 1975, tal seção foi reformulada, e todos os consultores da revista passaram a respondê-las, de acordo com a sua especialidade. Cada uma destas seções de cartas ocupava, geralmente, duas páginas por revista.

No período de 1996 a 2000, as cartas eram enviadas para uma única seção de cartas, intitulada "Pais \& Filhos Responde". As cartas eram respondidas, de acordo com seu conteúdo, por consultores das mais diferentes áreas. Neste período, a seção de cartas costumava ocupar 4 páginas por revista.

Em função de a maioria das cartas não mencionar o nome do consultor que a respondeu, optou-se por não registrar esta informação em nenhuma carta transcrita neste estudo, com exceção das que foram direcionadas ao Dr. Lins e Silva, que tinha uma seção própria.

\section{Detalhando os conteúdos das cartas sobre filhos de criação}

No período de 1975 a 1979 apenas 3 cartas abordaram o tema: filhos de criação. Todas se referiram a assuntos jurídicos, tendo sido respondidas pelo Dr. Haroldo Lins e Silva.

A primeira carta do período foi publicada em outubro de 1976 e levantou os direitos de herança de uma filha de criação. O leitor diz que sua esposa abandonou o lar após 42 anos de casamento e, entre outras dúvidas, pergunta: "Fizemos doação de todo o nosso patrimônio imobiliário para uma filha de criação, com reserva de usufruto para nós. Em caso de morte de um de nós dois, a renda ainda irá para esta nossa filha?" (Pais \& Filhos, out/1976, p. 65). A resposta dirigiu-se quase que totalmente para as outras dúvidas do leitor e finalizou dizendo: "Com relação ao usufruto, reverte no caso de morte de um, para o outro usufrutuário" (Pais \& Filhos, out/1976, p. 65). Sobre esta carta é oportuno comentar que foi categorizada como pertencente às famílias de criação devido ao leitor referir-se desta forma à sua filha, contudo, parece tratar-se de uma filiação adotiva diferente daquelas retratadas por Fonseca (1995) como famílias de criação. A carta não trouxe informações suficientes para um maior entendimento.

Outra carta tratou sobre os direitos da família de criação frente a um pai biológico que, depois de muito tempo, resolveu buscar seu filho:

O pátrio poder pode ser suspenso ou até extinto legalmente

Pouco antes de morrer, minha irmã me pediu que cuidasse de seu filho. Ele era um bebê, na época, e ela já havia se separado do marido. Hoje, passados seis anos e meio, o pai do menino apareceu e levou-o. Durante todo este tempo ele nunca procurou o filho ou the deu qualquer ajuda. Agora, além de tirá-lo de mim e de meu pai (o avô materno da criança), que o criamos, proibiu-nos de vê-lo ou tentarmos qualquer contato. Será que eu e meu pai, como tia e avô responsáveis pela criação do menor, até então, não temos nenhum direito, nem sequer de conviver com o menino? (M. G. $-R J)$

$\mathrm{O}$ pátrio poder pode estar sendo usado abusivamente pelo pai. Aliás, o pátrio poder é extinto ou suspenso, dependendo de circunstâncias que a lei determina (artigos 392/395, do Código Civil). Ao tempo da morte de sua irmã, podiam ter nomeado tutor para o menor, na pessoa do avô materno, devido à ausência do pai. Quando há destituição ou suspensão do pátrio poder, o juiz nomeia um tutor. $\mathrm{O}$ avô também tem o direito de nomear um tutor, na falta ou incapacidade dos pais, e pode pedir visitação aos netos. No caso, nem tanto por imperativo legal, mas por imposição natural e humana (Pais \& Filhos, jan/1978, p. 49). 
A terceira carta traz situação semelhante à segunda, porém, sob o ponto de vista da mãe que deu a filha para sua madrinha "cuidar":

Nem sempre a mãe é quem gera, mas quem cria Minha esposa foi mãe solteira. Como na época não dispunha de recursos, a madrinha dela levou a criança para cuidar e ficou com ela. Casamos depois e, hoje, podemos cuidar de nossa filha. Queremos ela de volta. A criança nasceu numa data e do registro, consta outra. (J. J. R. $-R J)$

Está na lei que ninguém pode reivindicar estado contrário ao que resulta do registro de nascimento, salvo provando-se erro ou falsidade do registro (artigo 348, do Código Civil). Nem sempre mãe é quem gera, mas quem cria. Atente bem para o interesse da criança e leve em conta os mais variados fatores, todos envolvendo o bem-estar e a segurança da menor. Antes de qualquer medida judicial, que pode ser precipitada, procure entendimentos pessoais com aqueles que estão exercendo as funções de pais da criança. Se houve grandeza na entrega, não moleste nem diminua a grandeza do ato primeiro (Pais \& Filhos, ago/1979, p. 88).

Vê-se nestas duas cartas o quanto a paternidade biológica é valorizada na nossa cultura, a ponto de alguns pais e mães biológicos acreditarem que o pátrio poder é um direito dado unicamente pela existência de laços de sangue, desconsiderando os "pátrios deveres" dele advindos.

As respostas de Lins e Silva demonstram outro valor presente na cultura, mas que só mais tarde viria a assumir maior destaque - a prioridade dada ao bemestar da criança. Entendendo que o interesse da criança devia ser priorizado, considerava que a manutenção da criança na família de criação era a solução mais adequada.

Os casos contados nas cartas também mostram o quanto as pessoas da época agiam às margens da lei oficial. Parece que não faziam termo de guarda, ou pelo menos não o mencionam nas cartas, e só recorriam ao tribunal quando aparecia um conflito.

Acredita-se que muitas dificuldades possam surgir para os profissionais dos Juizados no momento de decidir quem tem direito à guarda de uma criança, considerando-se que as pessoas têm histórias diferentes e, consequientemente, têm visões de família diferentes. É preciso cuidado para não desconsiderar práticas tradicionais de algumas comunidades de baixa renda, como a circulação de crianças, sem ignorar que "no plano institucional, seria inadmissível trabalhar com ideais diferentes para diferentes grupos" (Fonseca, 1999, p. 270). As diferenças precisam ser negociadas para se atingir o difícil objetivo de promover maior justiça social nos processos de adoção. Novamente salienta-se o papel fundamental da interdisciplinaridade frente a tais questões. Como afirma Tonin (2001), "Merece o Direito de Família um tratamento diferenciado no campo do Direito. Deve-se entendê-lo à luz da interdisciplinaridade, onde as outras ciências interagirão sem grau de hierarquia de funções, favorecendo o desfecho das questões de família e garantindo o bem-estar pessoal e social" (p. 364).

Duas cartas tiveram os filhos de criação por subtema entre 1975 e 1979, nas quais este tipo de filiação é apenas citado, sem, contudo, ser o assunto da carta. Uma das cartas é de uma leitora que trata sobre problemas conjugais e cita "Temos três filhos e mais uma menina que criamos" (Pais \& Filhos, jul/1975, p. 102). A outra carta é sobre problemas com a educação de um dos filhos, e apenas cita "Tenho seis filhos e crio uma sobrinha" (Pais \& Filhos, fev/1977, p. 105).

Entre 1996 e 2000 nenhuma carta teve os filhos de criação por tema. Apenas uma carta abordou este assunto como subtema (Pais \& Filhos, maio/1999, p. 8). Nesta carta, uma tia, que cria um sobrinho em função do falecimento da mãe deste (sua irmã), pergunta sobre o direito do sobrinho de receber a pensão que lhe é devida por parte do pai.

\section{CONSIDERAÇÕES FINAIS}

Verificou-se nas revistas Pais \& Filhos e Veja, de 1975 a 1979 e de 1996 a 2000, a quase inexistência de menções à prática da circulação de crianças no Brasil. Acredita-se que o fato de esta forma de organização de parentesco ser mais comum entre os pobres urbanos, aliado à falta de estudos sistemáticos, fez com que o assunto não fosse considerado relevante ou fosse mesmo desconhecido dos agentes dos media.

Ressalta-se que houve também poucas cartas de leitores publicadas na revista Pais \& Filhos sobre filhos de criação, porém, estas foram em maior número do que as reportagens ou menções espontâneas da revista sobre o assunto, principalmente no período de 1975 a 1979. Este dado é coerente com os achados da literatura, que revelam que a circulação de crianças entre a classe média era freqüente no país neste período. Deve-se considerar que a classe pobre, que ainda mantém esta prática, não tem acesso a revistas e, conseqüentemente, não lhes dirige cartas.

Acredita-se que caberá principalmente aos pesquisadores tornar a questão dos filhos de criação mais visível na imprensa e, conseqüentemente, mais visível para a sociedade em geral. Salienta-se, por isso, a 
necessidade de mais pesquisas sobre esta forma tradicional de filiação, ignorada até mesmo pela legislação. Em particular, sugere-se a realização de pesquisas transdisciplinares sobre a saúde mental dos brasileiros que "circularam" por diferentes famílias durante a infância e a adolescência, e seus sentimentos e representações em relação a tal prática.

\section{REFERÊNCIAS}

Abreu, D. (1998, outubro). Adotar uma criança brasileira: um verbo conjugado de várias maneiras. Trabalho apresentado no XXII Encontro Anual da ANPOCS. Caxambu. Obtido em 8 de fevereiro de 2001 do World Wide Web: http://www.terravista.pt/ipanema/2172/domingos. htm.

Badinter, E. (1980). O amor incerto - história do amor maternal do séc. XVII ao séc. XX. Lisboa: Relógio d'agua.

Charles, M. N. (1997). Filiation et don d'enfant en Polynésie française. Le Journal des Psychologues, 153, p. 28-32.

Costa, M. C. S. (1988). Os "filhos do coração" - adoção em camadas médias brasileiras. Dissertação de Mestrado, Universidade Federal do Rio de Janeiro.

Ezembé, F. (1977). Circulation des enfants en Afrique: d'hier à aujourd'hui. Le Journal des Psychologues, 153, p. $48-53$.

Fonseca, C. (1995). Caminhos da adoção. São Paulo: Cortez.

Fonseca, C. (1999). O abandono da razão: a descolonização dos discursos sobre a infância e a família. Em E. L. A. Sousa (Org.), Psicanálise e colonização: leituras do sintoma social no Brasil (p. 255-274). Porto Alegre: Artes e Ofícios.

Fonseca, C. (2000). The circulation of children in a Brazilian working-class neighborhood: a local practice in a globalized world. Anthropologie et Sociétés, 24, n. 3. (modified version).

Geertz, C. (2001). Nova luz sobre a antropologia. Rio de Janeiro: Jorge Zahar Ed.

Goody, E. (1982). Parenthood and social reproduction: fostering and occupational roles in West Africa. Londres: Cambridge University Press.

Rizzini, I. (1995). Crianças e menores - do pátrio poder ao pátrio dever: um histórico da legislação para a infância no Brasil (1830-1990). Em F. Pilotti \& I. Rizzini (Orgs.), A arte de governar crianças: a história das políticas sociais, da legislação e da assistência à infância no Brasil (p. 99-168). Rio de Janeiro: Instituto Interamericano Del Niño, Editora Universitária Santa Úrsula, Amais Livraria e Editora.

Sampaio, I. S. V. (2000). Televisão, publicidade e infância. São Paulo: Annablume; Fortaleza: Secretaria de Cultura e Desporto do Estado do Ceará.

Sorosky, A. D.; Baran, A. \& Pannor, R. (1989). The adoption triangle: sealed or opened records: how they affect adoptees, birth parents, and adoptive parents. San Antonio: Corona Publishing Co.

Tonin, M. M. (2001). O princípio do melhor interesse da criança e os limites do Direito: uma análise da jurisprudência brasileira. Tese de Doutorado, Universidade Federal do Paraná.

Velho, G. (1987). Família e subjetividade. Em A. M. Almeida; M. J. Carneiro \& S. G. Paula (Orgs.), Pensando a família no Brasil: da colônia à modernidade (p. 7987). Rio de Janeiro: Espaço e Tempo: UFRRJ.

Weber, L. N. D. (2001). Pais e filhos por adoção no Brasil: características, expectativas e sentimentos. Curitiba: Juruá.

\footnotetext{
Notas:

${ }^{1}$ Este artigo apresenta parte da dissertação de mestrado da primeira autora, orientada pela segunda, e defendida junto ao Programa de Mestrado em Psicologia da UFPR.

${ }^{2}$ Originalmente: "It is evident that, whatever the reasons for adoption, the parents usually treat a foster [adoptive] child with as much warmth and affection as they do their own".

${ }^{3}$ Revista semanal editada pela Editora Abril, escolhida por ser a revista informativa brasileira de circulação nacional com a maior tiragem (tiragem média atual de 1,1 milhão de exemplares).

${ }^{4}$ Revista mensal editada pela Editora Bloch, eleita por ser a revista brasileira especializada na área de família, sendo também de circulação nacional e com data de publicação coerente com a que se pretendeu estudar.

${ }^{5}$ Esta informação foi obtida através da Massa Falida de Bloch Editores S.A., responsável pela revista Nova Pais \& Filhos.
}

\section{Sobre as autoras}

Adriana Pellanda Gagno: Psicanalista; Psicóloga e Mestra em Psicologia pela UFPR. Endereço para correspondência: Rua XV de Novembro, 270 - sl. 503 - CEP: 80020-310 - Curitiba, PR - E-mail: apgagno@bol.com.br 
Lidia Natalia Dobrianskyj Weber: Professora do Departamento de Psicologia da UFPR; Coordenadora do Projeto Criança: desenvolvimento, educação e cidadania, da UFPR; Mestra e Doutora em Psicologia Experimental pela USP - E-mail: lidiaw@uol.com.br 